\title{
THE ROLE OF EDUCATION IN THE PROCESS OF INTEGRATION WITH THE EUROPEAN UNION: DUTIES AND RESPONSIBILITIES OF MARMARA UNIVERSITY
}

\section{Turay Yardımci**}

I rejoice to deliver this message to the students and the teaching staff at the European Community Institute on this very special "European Day", commemorating the integration in Europe in the past 50 years.

However, we deeply regret the passing away of our honoured opening lecturer at the European Community Institute, and a leading authority in European Law, Professor Dominik Lasok whose valuable academic contributions as well as his assistance in order to develop the research activities at the Institute need to be appreciated once more on this "European Day".

The Turkish Republic, as an integral part within the larger European family, aims to take its due place at every step of the ever-deepening European integration. All the institutions of higher education in Turkey, including our University, are bound to assume serious and comprehensive responsibilities throughout this process and ever continuously in the aftermath as well.

The Copenhagen criteria, that have been restated with greater emphasis at the Helsinki Summit in the last month of 1999, and pointed out as absolute conditions to be met on equal grounds by all the candidate countries for membership, require harmonisation of measures in all areas with the norms of the European Union. An inseperable dimension of European integration, that has been progressing through economic and monetary issues and eventually moving towards political unification, is without doubt the area of education.

The most important clue to the role of education can be found in the historic Sorbonne Declaration of 25 May 1998, in connection with celebrations of the $800^{\text {th }}$ anniversary of the University of Paris, Sorbonne. The said Declaration stressed the challenge in constructing the "European Area of Higher Education" and assuming the task of consolidating and enriching the European citizenship.

* The text of the statement delivered by the Rector of Marmara University, Professor Dr. Turay Yardımc1, to the European Community Institute, commemorating the $50^{\text {th }}$ anniversary of the "European Day" on 9 May 2000.

** Professor Dr., Rector of Marmara University. 
The creation of a "European Area" as the final goal will necessitate, according to the Declaration, that universities play a central role in enhancing the extraordinary cultural dimension of Europe as well.

Finally, the Declaration entitled "Towards a European Area for Higher Education", issued as the key document after the meeting of the European ministers in charge of education and the representatives from the world of higher education, on 19 June 1999 in Bologna, concentrated on the harmonisation of the architecture of higher education qualification systems in Europe. The main purposes of this Declaration, which was published as the "Bologna Declaration"1 and signed by the member countries of the European Union, as well as the European Economic Area and the Central and Eastern European countries that are candidates to the European Union, include detecting the areas of convergence in the structure of different systems of higher education in European countries, finding ways of achieving harmonisation between these systems, and identifying trends that may have an effect on the progress towards greater convergence of these structures in the future. It has also been emphasized in the Declaration, how cooperation in the effort to carry institutions of higher education through a process of reform, and convergence in order to create a congenial European space for higher education can at the same time strengthen stable, peaceful and democratic societies in Europe and especially in Southeastern European countries among which Turkey is also included.

Within the concept of a "European Area" in education, as described in the Declaration, and with the assurance of expanding a European higher education system, it was decided to take steps under the guidance of the following objectives: ${ }^{2}$

a. adoption of a system of easily readable and comparable degrees,

b. adoption of a system essentially based on two main cycles, undergraduate and graduate,

c. establishment of a system of credits- such as in the ECTS (European Credit Transfer System),

d. promotion of mobility by overcoming obstacles to the effective exercise of free movement with particular attention to students and university staff.

A "European Area of Higher Education" has implications in connection with another crucial subject that is closely related with a more flexibly adaptable system of different degree types in higher education; this subject is the freedom of movement and the freedom of establishment of Turkish workers and professionals, respectively, which is expected to be of greater concern in the future. 
Diplomas received in Turkey may cause problems in their recognition by. the institutions of higher learning in European countries today and a to a greater extent after Turkey's membership in the EU will be realized. The need for convergence in the higher education systems of different countries has already been felt as a necessity in the European Area. In the diverse means of credit transfers, in the subject of "bridging courses", in the differences between systems made up of modules and those based on a philosophy of integrated studies which follow a continuous academic progression, and in the recognition of final qualifications as expressed in a diploma ${ }^{3}$, presently, are among the problem areas even in the EU member countries, posing as an obstacle, for the freedom of movement of their own citizens.

This has its implications upon Marmara University as well, where academic programmes are carried on in three different European languages, in addition to those in Turkish, and improvements will bring greater ease for the foreign students admitted in the recognition of the diplomas they had received in their own countries, and provide assurance about their prior learning and exemption from certain studies. ${ }^{4}$ Similarly, our own graduates will benefit from improved international ease and transparency of credit transfers and better recognition procedures of diplomas and academic standing.

It should be deemed as vital that Turkey also adopts itself to the radical reforms anticipated in the area of higher education in Europe today. Especially after the declaration at the Helsinki Summit in December 1999, that Turkey is included among the list of candidate countries for membership in the European Union, Turkey cannot afford to remain in the back of the developments, especially in the area of education.

Furthermore, again in connection to such progress achieved, Turkey has finally been admitted into the SOCRATES Programme of the European Union. The SOCRATES (I), while in the beginning comprised only the 1995-1999 period of time, SOCRATES (II) which now intends to cover the time span, 2000-2006, was unintermittently put into application after much favourable results had been obtained from the first experiment. Turkey, unfortunately, did not have the chance to partake in SOCRATES (I); now it is a remarkably positive development for Turkey to have this chance of participation in SOCRATES (II). This chance also imposes upon all the staff at Turkish universities many difficult tasks and especially upon us at Marmara, a university where the education provided expands beyond the immediate national borders and far into the horizons.

According to Decision No. $253 / 2000^{5}$, reached on 24 January 2000 by the EU Council of Ministers and the European Parliament, a budget of 1.850 
million Euro has been allocated for SOCRATES (II) Programme. The SOCRATES Programme has significant objectives such as to create a "Europe of Knowledge", to achieve quality assurance and enhancement based on an open system of education and through cooperation in the search for excellence, the "Europeanisation" of higher education through the emphasis of the cultural and scientific traditions of Europe, to enhance the development through education of the individual person as a citizen of Europe and increase his chances for satisfactory employment opportunities.

The SOCRATES Programme comprises all phases of education, including even pre-school education. However, the dimension that concerns our university directly is ERASMUS, which is a sub-programme providing for cooperation among European universities in the mobility of students as well as the exchanges among members of the teaching staff. While this will make possible for our students to have a chance for studies up to one year at any European university, enhancing their knowledges, improving their capacities and gaining experience in interaction with young persons of diverse European cultural areas, our teaching staff will also benefit greatly from the programme by taking part in shared projects with European colleauges and acquire additional expertise in their branch of study.

Another sub-programme of SOCRATES, having direct relevance to our university, is LINGUA which aims to further the learning of European languages. Turkey's growing integration with Europe as well as with the world as a result of the ongoing trend of globalization, requires that the Turkish youth should become proficient in at least one foreign language.

Marmara University has tried to do the utmost in the subject of foreign language acquisiton by devising course programmes in a foreign language, by offering its academic programmes in a foreign language and by setting up a department and a research center for studies on foreign languages.

Within the process of deepening integration in Europe, universities are bound to assume responsibilities comprehensively relating to the education and training of individuals in order to equip them with the knowledge required to fulfill the conditions for membership in the European Union and also to have the capacity to adopt the characteristics of European citizenship. Universities' priorities are no doubt in the creation of manpower of higher occupational quality and scientific expertise, being in command of the "state of the art" according to European and world standards. We all know that budgetary resources allocated to education in Turkey are well below the desired level. A meaningful comparison emerges when one investigates the rates out of the national income allocated to education in the four Eastern European 
countries which are candidates for EU membership: In Poland, Hungary, Romania and Bulgaria, the rates are 5.2\%, 5.3\%, 3\% and 4\%, respectively. Whereas in Turkey, in 1995, the rate of resource allocation for all the branches of education, including higher education, was only $2.2 \%$; what is even more striking is the fact that the same rate was valid for education in the year 1980 as well. ${ }^{6}$

At Marmara University, the trend is towards taking a part in the space designated as the "European Area of Higher Education" alongside other prestigious universities of Europe. At this contemporary institution of higher learning, there has been a long term exertion towards this worthwhile goal. Marmara University no doubt fulfills such extensive objectives already by offering academic programmes in four different languages. The numbers of students and teaching staff who are in mobility have also been on the rise remarkably through recent years. ${ }^{7}$ A process of restructuring has been started in all the units of Marmara University (faculty, school, institute and research center) (Figure 1) in order to meet the needs of education towards a "Europe of Knowledge". Most of all, the greatest contributions as part of this overall new effort are naturally expected from the European Community Institute of Marmara University.

The European Community Institute was established in 1987 in order to educate individuals to become competent in European subjects so as to prepare them for employment both in the public and private sectors in the years that would follow. The application of Turkey for membership in the European Community was made in the same year. While Marmara is the only university in Turkey where European studies are undertaken at the Institute status, it is also an indication of the extent to which our university has dedicated itself to this subject even thirteen years ago.

Granting postgraduate degrees in European studies, mainly anchored upon highly interdisciplinary programmes, the European Community Institute has also opened the way for the possibility of deeper specialization by dividing the programmes into three main areas: The law of the European Union; the Economics of the European Union and the political structure of the EU. The Institute has thus succeeded in achieving total convergence with the course programmes in relation to the EU studies offered at corresponding centers at the higher institutions of learning in Europe.

The mutual exchanges of teaching staff that have been included in the ERASMUS Programme of the European Union, have already been realized to a greater extent by the European Community Institute, even long before Turkey's recent acceptance into the framework of SOCRATES (II) starting from the 


\section{Figure 1: Institutional Structure of Marmara University}

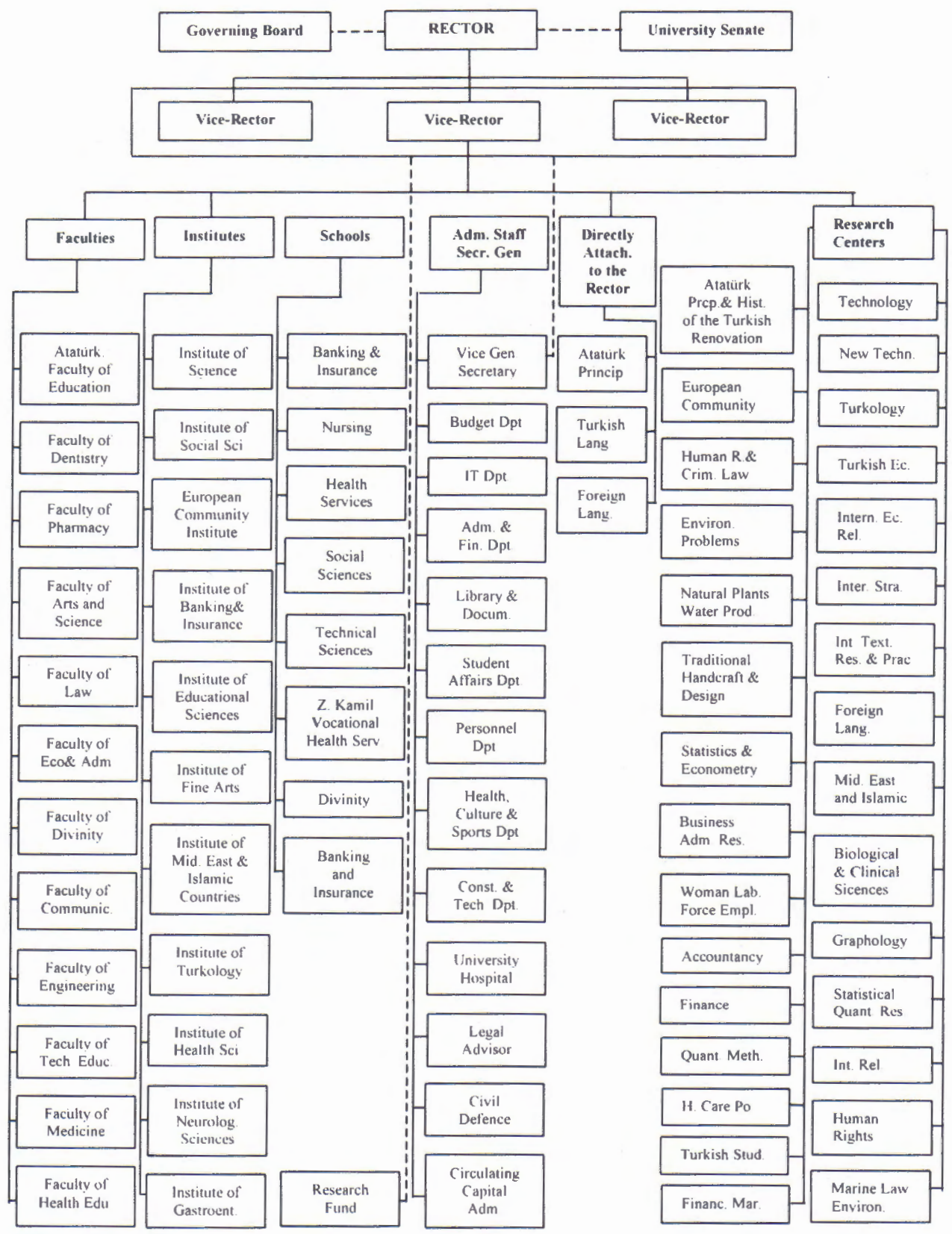


year 2000 . Within the exchange activity promoted by the Marmara EC Institute, nearly 70 visits have been realized by members of the teaching staff from a variety of European universities as well as EC experts and academics working on European subjects who have been assigned to temporary teaching posts and have given courses at the European Community Institute. No doubt, one may count with great pride among these persons of distinction, the late Professor Dominik Lasok, who is accepted globally as a leading authority on the subject of European law. His works will ever survive now that he is deceased.

The Turkish members of the teaching staff at the EC Institute, in turn, have carried on postgraduate or research studies in European subjects. Included among such institutions, the London School of Economics, the University of Exeter, the University of Essex, European University Institute in Florence and the College of Europe in Brugges, may be cited.

The Jean Monnet Financial Agreement, signed in $1989,{ }^{8}$ no doubt played a crucial role in the achievement of this student and teacher mobility to such an extent. The said Programme, comprising financial contributions by the European Community, especially intended for use in higher education in order to strengthen the ties between Turkey and the European Community, continued for seven years. The recognition of the diplomas, granted by the Marmara EC Institute upon completion of this Programme, has been achieved by many prominent universities in Europe.

The Institute also started course programmes that have been attracting students from abroad, increasing the numbers of foreign applications. I was much pleased to hear from a number of Rectors of European universities, that they were already informed of Marmara University and the European Community Institute and that they wished to enter into cooperation with our university. One example worth citing here is Professor Hagen Lichtenberg, the ViceRector at the University of Bremen, who visits the Institute each year and conducts a seminar. Another favourable appraisal came from Professor Stephen Wilks the Vice-Rector of Exeter University. Such developments, in a way, provide evidence that the Institute is on its way of taking a part in the abovementioned "European Area of Higher Education". However, one important issue we need to follow with great intent, as the Rectorate of Marmara University, is to start negotiations with the concerned authorities in the EU in order to revitalize the cited Jean Monnet Programme and to renew the Agreement which will certainly help improve the quality of the education we provide at the European Community Institute.

A significantly special connection of the European Community Institute is in respect of the European Community Studies Association (ECSA), with 
headquarters in Brussels, enjoying over 5000 in membership and receiving financial support from the Commission of the European Union. This association of academicians who carry on studies covering various subjects of the European Union, has its Turkish branch, Turkish Universities Association for European Community Studies, TUNAECS. TUNAECS, conducting works in harmony with the aims of ECSA, is an umbrella organisation establishing a platform for members of the academia in Turkey who give courses on European integration or carry on academic research on European subjects. I should add with great pleasure that the European Community Institute of Marmara University successfully coordinates the Turkish extension of ECSA and can boast of the following basic activities: ${ }^{9}$

1. promoting teaching and university research on European integration;

2. developing cooperation among its members and, through them, realizing the widest possible cooperation between universities;

3. managing transnational programmes of research and technical assistance, organising conferences and stimulating networks of academic cooperation, making available its expertise in relation to curricula and programmes and carrying out studies in the area of European integration;

4. disseminating information on university activities relating to teaching and research on European integration through publications and by establishing, managing and contributing to an interactive communication network on the internet.

When it is taken into consideration that ECSA's aims, cited above, are also in harmony with the Bologna Declaration, the relations between our University and ECSA are to be applauded with respect to advancement towards the final objectives as stipulated in the Declaration. For the first time in our university, we have given priority, as the Rectorate, to proposals for research projects on the European Union and the ongoing process of integration in Europe so that, in the aftermath of the Helsinki Summit whereby we have acquired the status of "candidacy" for EU membership, Turkey can take its due place in the "European Area for Higher Education". Seven such proposals for research projects to be conducted by the staff at the European Community Institute have been accepted this year

Another important subject that needs to be discussed with respect to our university as well as other universities in Turkey is the "Jean Monnet Chairs of European Studies" that have been formed in many universities in the Member States of the European Union as well as in a number of non-member candidate countries in Eastern Europe. Within the framework of this programme that is financed by the European Union and that has been initiated in order to encourage and support studies concerning the basic issues of the European Union and the 
process of integration in Europe, an incredible number of research projects, 2322 at the moment, have already been launched; 491 Jean Monnet Chairs have been set up; 800 Permanent Courses put into operation; and, 641 "European Modules" have been brought to life. Besides the institutions of higher learning in the European Union, institutions that have received financial support from the Jean Monnet Chairs Programme number as 5 in the Czech republic, 33 in Poland and 14 in Hungary. ${ }^{10}$

We thus see it as a very important task before us to start the Jean Monnet Chairs Programme in our country as well, and aim to initiate in Turkey the application of European Union support for the chairs that are already operating successfully in the subjects of European Union law, European Union economy and European Union political structure, within the regular course programmes of the European Community Institute of Marmara University.

It should also be our duty to pay tributes to the periodical, "Marmara Journal of European Studies", published biannually by the European Community Institute and which is the only academic Journal on inter-disciplinary studies concerning Turkey/European Union relations in Turkey. In the Journal, which is distributed both in Turkey and abroad, academic works of many Turkish as well as foreign writers of distinctive academic standing take place. It is to our utmost satisfaction that the Journal communicates to a great variety of sectors in the subject of Turkey/EU relations.

In conclusion, I would like to extend my gratitude to Professor Orhan Oğuz who is the founding rector of our university and who has contributed the most in upgrading Marmara to be rated among the top three universities in Turkey; to professor Haluk Kabaalioğlu who has exerted the greatest effort in the establishment of the European Community Institute and who is presently the president of TUNAECS and is a leading academician on the subject of Turkish/European integration; the staff at the EC Institute, starting from the Director, who has ever done his utmost in much sacrificial work, to each and every one of the dedicated research assistants, and to all colleagues, native or foreign, who have made invaluable contributions to the programmes at the EC Institute as lecturers or instructors. I hope further successes will accrue in all the initiatives of the European Community Institute in the future. 


\section{Endnotes:}

${ }^{1}$ Visions of a European Future: Bologna and Beyond, Trends and Issues in European Higher Education, produced by Guy Haug and Jette Kirstein for the Confederation of EU Rectors' Conferences and the CRE (Association of European Universities), http://www.eaie.nl/about/comments/speech.html

${ }^{2}$ See, Joint declaration of the European Ministers of Education convened in Bologna on the $19^{\text {th }}$ of June 1999, http://www.aeie.nl/about/comments/Bologna.html

${ }^{3}$ Trends in Learning Structures in Higher Education; Information on Learning Structures of Higher Education in the EU/EEA Countries, by Jette Kirstein, http://www.rks.dk/trends2.htm

4 The total number of foreign students registered in Marmara University in the year 2000 is 694, and 98 of them are from the EU countries. 160 of the students are postgraduate students.

${ }^{5}$ Decision No. 253/2000/EC of 24 January 2000 (OJ L 28, 3 February 2000) establishing the second phase of the Community action programme in the field of education 'Socrates'. http://europa.eu.int/comm/education/socrates/decsoc2_en.pdf

${ }^{6}$ DEIK, Turkey 1999 An International Comparison, p.32. (from, UNESCO Statistical Yearbook, 1998).

${ }^{7}$ To cite an example, the total number of the teaching staff of Marmara University who conducted research and/or offered lectures in foreign universities in the first 6 months of the year 2000 is 75 .

8 Resmi Gazete (Turkish Official Gazette) 27 November 1989, no. 20355.

${ }^{9} \mathrm{http}: / /$ www.ecsanet.org/about.htm

${ }^{10} \mathrm{http}: / /$ europa.eu.int/comm/dg10/university/ajm/index_en.html 